\title{
HUBUNGAN ASUPAN LEMAK DAN RASIO LINGKAR PINGGANG PANGGUL (RLPP) DENGAN KADAR LOW DENSITY LIPOPROTEIN (LDL) PADA WANITA MENOPAUSE DI POSYANDU NGUDI WALUYO SURAKARTA
}

\author{
Nesti Rahmawati ${ }^{1}$, Setyaningrum Rahmawaty ${ }^{2}$, Elida Soviana ${ }^{3}$ \\ ${ }^{1}$ Alumni Program Studi S1 Gizi FIK UMS. Jl. A. Yani Tromol Pos I Pabelan Surakarta. \\ Email: ${ }^{1}$ Nestir@ymail.com \\ ${ }^{2,3}$ Program Studi Ilmu Gizi FIK UMS. Jl. A. Yani Tromol Pos I Pabelan Surakarta. \\ Email: ${ }^{2}$.Setyaningrum.Rahmawaty@ums.ac.id, ${ }^{3}$ elida.soviana@ums.ac.id
}

\begin{abstract}
ABSTRAK
Disamping faktor hormonal tingginya asupan lemak dan rasio lingkar pinggang panggul (RLPP) diakui sebagai faktor pencetus peningkatan kadar LDL pada wanita menopause. Penelitian ini bertujuan untuk mengetahui hubungan asupan lemak dan RLPP dengan kadar LDL pada wanita menopause. Penelitian ini termasuk studi crossectional yang melibatkan 33 wanita menopause usia 45-65 tahun dengan teknik simple random sampling di Posyandu Ngudi Waluyo Surakarta. Asupan lemak dihitung dari rata-rata food recall 24 jam selama 3 hari dengan menggunakan Nutrisurvey. Rasio lingkar pinggang panggul diukur menggunakan metlin dan dilakukan sebanyak 2 kali. Kadar LDL diukur dengan pengambilan darah vena menggunakan metode Enzimatik. Tujuh belas $(51,5 \%)$ responden memiliki asupan lemak tergolong tinggi, $26(78,8 \%)$ responden memiliki RLPP tergolong tinggi $(\geq 0,85 \mathrm{~cm})$ dan $15(45,5 \%)$ responden memilik kadar LDL tergolong tinggi $(\geq 150 \mathrm{mg} / \mathrm{dL})$. Hasil uji korelasi antara tingkat asupan lemak dengan kadar LDL menunjukkan nilai $\mathrm{p}=0,261$ sedangkan untuk rasio lingkar pinggang panggul dengan kadar LDL menunjukkan nilai $\mathrm{p}=0,67$. Baik asupan lemak maupun RLPP tidak berhubungan dengan kadar LDL pada wanita menopause di Posyandu Ngudi Waluyo Surakarta.
\end{abstract}

Kata Kunci: Asupan Lemak, Kadar LDL, Menopause, RLPP

\begin{abstract}
Beside hormonal factors, high intake of fat and waist to hip ratio (WHR) are predicted as risk factorstothe increasing of LDL levels in menopause women. The aim of the present study was to assess association fat intake and WHR with LDL levels in menopause women. A cross sectional study was conducted in a simple random sample of 33 menopause women aged 45-65 years in Posyandu Ngudi Waluyo Surakarta. An average of three 24-hour dietary recalls of each woman was analysed using Nutrysurvey to obtain fat intake. WHR and LDL concentration each respondent were undertake. Seventeen $(51.5 \%)$ participants had high intake of fat, 26 (78.8\%) participants with WHR more than $0,85 \mathrm{~cm}$ and $15(45 \%)$ had LDL concetration
\end{abstract}


above $150 \mathrm{mg} / \mathrm{dL}$. There was no relationship between fat intake and LDL concentration $(\mathrm{p}=0.139)$ as well as WHR and LDL levels $(p=0.67)$. Both fat intake and WHR appeared not to be the risk factor to the increasing of LDL level in menopause women at the Posyandu Ngudi Waluyo Surakarta.

Keywords: Fat Intake, LDL Level, Menopause, Waist to Hip Ratio

\section{PENDAHULUAN}

Menjadi tua (menua) merupakan suatu tahapan dimana pertumbuhan dan perkembangan mulai berhenti secara bertahap, sehingga fungsi tubuh mengalami perubahan. Perubahan fungsi tubuh dimulai dari penurunan fungsi jaringan otot, penurunan fungsi organ tubuh hingga penurunan fungsi hormon. Perubahan-perubahan yang terjadi dapat berdampak pada kesehatan lanjut usia (lansia) (Fatmah, 2010).

Menopause merupakan kejadian alamiah yang dialami wanita ketika fungsi hormon penting seperti progesteron dan esterogen telah berhenti fungsi (Spencer, 2007). Fungsi hormon esterogen dan progesteron yang menurun mengakibatkan kadar Low Density Lipoprotein (LDL) menjadi tinggi dan sulit untuk dikendalikan. Hal tersebut meningkatkan risiko penyakit jantung dan pembuluh darah pada wanita menopause (Khomsan, 2003). Selain faktor hormonal tinggi rendahnya kadar LDL dipengaruhi oleh genetik, usia, jenis kelamin, obat-obatan, aktivitas fisik, kebiasaan merokok, obesitas dan asupan makan yang tinggi lemak (Bull 2007, Khomsan 2003 dan Waspadji 2010).

Asupan makan yang tinggi lemak akan menurunkan ekskresi kolesterol serta menurunkan aktivitas pengambilan LDL oleh reseptor LDL. Reseptor LDL yang jumlahnya tidak mencukupi menyebabkan LDL banyak yang tidak terangkap, akibatnya kadar LDL akan meningkat dan akan lebih lama berada dalam sistem sirkulasi yang memungkinkan LDL teroksidasi. Low Density Lipoprotein yang teroksidasi inilah yang berbahaya karena memiliki sifat aterogenik atau menyebabkan penumpukan dan pengendapan di pembuluh darah yang meningkatkan risiko aterosklerosis (Bull, 2007). Hasil penelitian yang dilakukan oleh Nuraeni (2012), menyatakan bahwa terdapat hubungan antara kebiasaan konsumsi lemak dengan kadar LDL pada dosen dan karyawan Universitas Sliwangi. Sebanyak $66,7 \%$ partisipan yang memiliki kadar LDL tinggi sebagian besar memiliki kebiasaan sering mengkonsumsi lemak sedangkan $33,3 \%$ yang memiliki kadar LDL normal sebagian besar jarang mengkonsumsi lemak.

Status gizi seseorang dapat dipengaruhi oleh konsumsi makanan berlemak yang berlebih. Pengukuran status gizi dengan menggunakan pengukuran rasio lingkar pinggang panggul (RLPP) dapat digunakan untuk mendeteksi penyebaran lemak pada jaringan adiposa (Waspadji, 2003). Jaringan adiposa terdapat di seluruh bagian tubuh, salah satunya di perut. Lemak yang berada pada dinding perut lebih berisiko dibandingkan penimbunan di tempat lain. Sel-sel lemak yang berada pada dinding perut memiliki ukuran lebih besar dan didominasi oleh LDL. Timbunan lemak yang semakin banyak di dalam rongga perut akan diikuti dengan tingginya kadar LDL. Peningkatan kadar LDL akan menyebabkan terjadinya aterosklerosis dan meningkatkan risiko terjadinya penyakit jantung dan pembuluh darah (Soeharto, 2004).

Hasil penelitian Sunarti (2013) menunjukkan bahwa seseorang dengan 
RLPP besar untuk laki-laki $>0,90 \mathrm{~cm}$ dan perempuan $>0,77 \mathrm{~cm}$ memiliki $1,76 \mathrm{kali}$ berisiko menderita PJK dibandingkan dengan yang RLPP normal. Rata-rata seseorang yang memiliki pinggang yang besar juga memiliki panggul yang besar karena adanya penumpukan lemak di rongga perut (Williams, 2007).

Hasil survey pendahuluan yang dilakukan pada bulan Agustus 2015 di Posyandu Ngudi Waluyo didapatkan data $60 \%$ wanita menopause memiliki kadar LDL $>130 \mathrm{mg} / \mathrm{dL}$. Hal ini menunjukkan risiko terjadinya penyakit degeneratif seperti jantung koroner cukup tinggi.

Berdasarkan latar belakang di atas maka peneliti akan meneliti tentang hubungan tingkat asupan lemak dan RLPP dengan kadar LDL pada wanita menopause di Posyandu Ngudi Waluyo Surakarta.

\section{METODE PENELITIAN}

Desain penelitian ini cross sectional dilakukan pada bulan Agustus 2014 sampai bulan November 2015 di Posyandu Ngudi Waluyo Surakarta.

\section{Responden}

Sebanyak 33 wanita menopause terlibat dalam penelitian ini yang direkrut menggunakan teknik Simple Random Sampling. Cara pengambilannya dengan mengundi semua populasi yang sesuai kriteria inklusi dan eksklusi dengan sistem undian. Undian yang keluar pertama adalah sampel pertama dan seterusnya sampai diperoleh jumlah 30 sampel yang telah ditetapkan.

\section{Data asupan lemak}

Pengumpulan data asupan lemak dengan cara menanyakan makanan (wawancara langsung) dengan menggunakan food recall 3 x 24 jam secara tidak berurutan dengan jeda satu hingga dua hari, yang kemudian dianalisis dengan software Nutrisurvey.

\section{Data RLPP}

Data RLPP diperoleh dengan cara melakukan pengukuran dengan menggunakan pita ukur atau metlin dengan ketelitian $0,1 \mathrm{~cm}$ yang dilakukan 2 kali ulang. Rata-rata RLPP dari 2 kali pengukuran tersebut digunakan untuk mengetahui banyaknya lemak di rongga perut. Kategori RLPP dibagi menjadi dua kelompok yaitu, RLPP normal jika $<0,85$ $\mathrm{cm}$ dan tinggi jika $\geq 0,85 \mathrm{~cm}$ (WHO, 2008).

\section{Data kadar LDL}

Kadar LDL darah diperoleh dari pemeriksaan darah vena dengan menggunakan metode Enzimatik. Kategori kadar LDL dibagi menjadi tiga kelompok yaitu, kadar LDL optimal jika $\leq 129$ $\mathrm{mg} / \mathrm{dL}$, garis batas tinggi jika 130-149 $\mathrm{mg} / \mathrm{dL}$ dan tinggi jika $\geq 150 \mathrm{mg} / \mathrm{dL}$.

\section{Analisis data}

Analisis data disajikan dalam tabel distribusi dari variabel yang diteliti meliputi asupan lemak, RLPP dan kadar LDL, untuk mendeskripsikan data yang diperoleh berupa distribusi dan persentase. Analisis uji statistik antara asupan lemak dan kadar LDL menggunakan uji Sparman's Coefficient Correlation sedangkan analisis uji statistik antara RLPP dan kadar LDL menggunakan uji Pearson Product Moment.

\section{HASIL DAN PEMBAHASAN}

\section{Karakteristik Responden}

Sesuai hasil penelitian, diperoleh data karesteristik subjek penelitian meliputi distribusi berdasarkan usia, tingkat pendidikan dan jenis pekerjaan, dapat dilihat pada Tabel 1 . 
Tabel 1.

Karakteristik Responden ( $\mathrm{n}=33)$

\begin{tabular}{lcc}
\hline Karakteristik & $\mathrm{N}$ & $\%$ \\
\hline Usia & & \\
45-59 Tahun & 23 & 69,7 \\
60-65 Tahun & 10 & 30,3 \\
\hline Tingkat Pendidikan & & \\
Tidak Sekolah & 5 & 15,2 \\
SD & 21 & 63,6 \\
SMP & 3 & 9,1 \\
SMA/SMK & 3 & 9,1 \\
PT & 1 & 2,0 \\
\hline Jenis Pekerjaan & & \\
Guru & 1 & 3,0 \\
Tidak & 21 & 63,6 \\
bekerja/IRT & & \\
Karyawan & 2 & 6,1 \\
Swasta & 9 & 27,3 \\
\hline Asupan Lemak & & \\
Baik & 16 & 48,5 \\
Tinggi & 17 & 51,5 \\
\hline Rasio Lingkar Pinggang Panggul & \\
Normal & 7 & 21,2 \\
Tinggi & 26 & 78,8 \\
\hline Kadar Low Density Lipoprotein & \\
Optimal & 12 & 36,4 \\
Garis Batas & 6 & 18,2 \\
Tinggi & & \\
Tinggi & 15 & 45,5 \\
\hline \multicolumn{2}{l}{}
\end{tabular}

Berdasarkan Tabel 1, diketahui $69,7 \%$ berusia $45-59$ tahun. Tingkat pendidikan responden diketahui sebanyak $63,6 \%$ responden memiliki tingkat pendidikan SD. Menurut Syafiq (2013), bahwa tingkat pendidikan dapat mempengaruhi kemampuan menerima dan mengolah informasi yang diperoleh menjadi suatu perlakuan yang dapat mempengaruhi kesehatan seseorang. Jenis pekerjaan paling banyak yang dimiliki responden adalah tidak pekerja/IRT sebanyak 63,6\%. Banyaknya responden yang tidak bekerja/IRT menyebabkan rendahnya daya beli terhadap bahan makanan, jika daya beli terhadap makanan rendah maka tidak menutup kemungkinan asupan gizi juga menurun (Madanijah, 2004).

Asupan lemak dengan kategori tinggi (>30\% total energi) sebesar 51,5\% (17 orang) hampir sama dengan asupan lemak dengan kategori baik $(\leq 30 \%$ total energi) sebesar 48,5\% (16 orang). Angka asupan lemak minimal pada wanita menopause adalah sebesar $13 \%$ dari total kebutuhan dan asupan maksimal sebesar $54 \%$ dari total kebutuhan dengan rata-rata asupan lemak sebesar $32 \%$ dari total kebutuhan. Responden yang memiliki asupan lemak tinggi lebih sering mengkonsumsi makanan dengan cara pengolahan digoreng dan memasak sayur dengan campuran santan.

Berdasarkan Tabel 1 rasio lingkar pinggang panggul responden sebagian besar responden memiliki RLPP yang tinggi yaitu $78,8 \%$ (26 orang) dan sebanyak $21,2 \%$ ( 7 orang) memiliki RLPP yang normal sebanyak 40 orang $(95,2 \%)$. Pengukuran RLPP digunakan untuk mengetahui timbunan lemak dalam rongga perut, penurunan berat badan dan untuk mengetahui tingkat risiko penyakit yang berhubungan dengan kelebihan berat badan seperti penyakit jantung, diabetes melitus dan stroke (Mueller dan Nicole, 2008).

Sebagian responden memiliki kadar LDL yang tinggi yaitu 45,5\% (15 orang), sebagian lagi memiliki kadar LDL yang optimal yaitu $36,4 \%$ (12 orang) dan sebanyak $18,2 \%$ (6 orang) dengan kategori tinggi. Faktor penyebab kadar LDL tinggi salah satunya adalah usia. Wanita yang telah memasuki usia menopause kadar LDL akan cenderung meningkat. Hal ini disebabkan oleh hormon esterogen yang berfungsi sebagai antioksidan (mencegah proses oksidasi) turun secara drastis sehingga menyebabkan LDL dapat menembus plak di pembuluh darah yang mengakibatkan penyumbatan pembuluh darah (Khomsan, 2002).

\section{Hubungan Asupan Lemak dengan Kadar Low Density Lipoprotein}

Asupan lemak responden didapatkan dari recall 24 jam yang dilakukan selama 
3 hari secara tidak berurutan. Distribusi asupan lemak dan kadar LDL dapat dilihat pada Tabel 2.

Tabel 2. Hubungan Asupan Lemak dan Kadar LDL pada Wanita Menopause

\begin{tabular}{ccccc}
\hline Variabel & Mean & $\begin{array}{c}\text { Std. } \\
\text { Deviasi }\end{array}$ & Median & $\begin{array}{c}p \text { - } \\
\text { value* }\end{array}$ \\
\hline $\begin{array}{c}\text { Asupan } \\
\text { Lemak }\end{array}$ & 25,77 & 11,34 & 22,77 & \\
$\begin{array}{c}\text { Kadar } \\
\text { LDL }\end{array}$ & 142,22 & 35,62 & 143,44 & 0,261 \\
\hline
\end{tabular}

*Uji Rank Sperman

Berdasarkan Tabel 2 menunjukkan bahwa nilai mean asupan lemak dan kadar LDL adalah 25,77 dan 142,22. Nilai median asupan lemak dan kadar LDL adalah 22,77 dan 143,44 sedangkan nilai simpang baku (standart deviation) asupan lemak dan kadar LDL adalah 11,34 dan 35,62 .

Uji hubungan antara asupan lemak dengan kadar LDL menggunakan uji statistik korelasi Rank Sperman menunjukukkan nilai $p$-value 0,261 $(p \geq 0,05)$. Hal ini berarti tidak ada hubungan antara asupan lemak dengan kadar LDL pada wanita menopause. Hasil penelitian ini sejalan dengan penelitian yang dilakukan oleh Adhiyani (2013), tidak terdapat hubungan antara konsumsi lemak dengan kadar kolesterol pada lansia di Kelurahan Serengan Surakarta.

Tidak semua wanita menopause yang mengkonsumsi makanan berlemak memiliki kadar LDL yang tinggi, hal ini dikarenakan tingkat kesadaran responden yang tinggi terhadap kesehatan yang dapat dilihat dari banyaknya wanita menopause yang datang ke posyandu serta seringnya melakukan aktivitas ringan seperti senam pagi dan jalan sehat yang diselenggarakan pihak posyandu rutin selama dua kali dalam sebulan. Kegiatan tersebut dilakukan untuk meningkatkan daya tahan tubuh sehingga terhindar dari penyakit, meningkatkan kebugaran tubuh, meningkatkan kelenturan tubuh, membangun kesetiakawanan sosial dan lain sebagainya (Fatma, 2010). Hal lain seperti lebih sering mengkonsumsi makanan dengan sumber lemak tak jenuh, tidak adanya faktor stress dan tidak adanya faktor keturunan (Djohan, 2004).

\section{Hubungan Rasio Lingkar Pinggang Panggul dengan Kadar Low Density Lipoprotein}

Rasio lingkar pinggang panggul diperoleh dari pengukuran lingkar pinggang dan panggul menggunakan metlin yang dilakukan 2 kali. Distribusi RLPP dan kadar LDL dapat dilihat pada Tabel 3.

Tabel 3. Hubungan RLPP dan Kadar LDL pada Wanita Menopause

\begin{tabular}{ccccc}
\hline Variabel & Mean & $\begin{array}{c}\text { Std. } \\
\text { Deviasi }\end{array}$ & Median & $p$-value* \\
\hline RLPP & 0,88 & 0,069 & 0,89 & \\
$\begin{array}{c}\text { Kadar } \\
\text { LDL }\end{array}$ & 142,22 & 35,62 & 143,44 & 0,674 \\
\hline
\end{tabular}

*Uji Korelasi Product Moment

Berdasarkan Tabel 3 menunjukkan bahwa nilai mean RLPP dan kadar LDL adalah 0,88 dan 142,22 . Nilai median RLPP dan kadar LDL adalah 0,89 dan 143,44 sedangkan nilai simpang baku (standart deviation) RLPP dan kadar LDL adalah 0,069 dan 35,62.

Uji hubungan antara RLPP dengan kadar LDL menggunakan uji statistik korelasi Product Moment menunjukkan nilai $p$-value $0,674 \quad(p \geq 0,05)$. Hal ini berarti tidak ada hubungan antara RLPP dengan kadar LDL pada wanita menopause. Hal tersebut sejalan dengan penelitian yang dilakukan oleh Putri (2014), bahwa tidak ada hubungan antara rasio lingkar pinggang panggul dengan kadar kolesterol pada wanita usia diatas 40 tahun. Penelitian tersebut juga sejalan dengan penelitian yang dilakukan Suparjo (2010), tidak terdapat hubungan rasio lingkar pinggang panggul dengan kadar kolesterol pada pasien jantung di 
Poliklinik Jantung RSUD DR. Moewardi Surakarta.

Salah satu faktor yang dapat mempengaruhi kadar LDL yaitu usia. Memasuki usia menopause, wanita cenderung memiliki kadar LDL yang tinggi akibat dari penurunan kadar hormon esterogen, dimana hormon ini memiliki fungsi menjaga kadar HDL tetap tinggi dan kadar LDL tetap rendah (Maulana, 2007). Kondisi inilah yang menyebabkan wanita sebelum menopause memiliki tingkat proteksi lebih baik dibandingkan ketika telah memasuki usia menopause. Menurunnya hormon esterogen juga menyebabkan jumlah lemak tubuh meningkat, terutama lemak pada bagian pinggul, perut dan dada. Jumlah lemak tubuh yang meningkat, laju metabolisme menurun serta aktivitas fisik yang juga menurun dapat menyebabkan energi yang seharusnya digunakan akan disimpan dalam bentuk timbunan lemak. Timbunan lemak di bagian abdomen menyebabkan RLPP pada wanita menopause cenderung meningkat (Wirakusumah, 2004 dan Spencer, 2007).

\section{KESIMPULAN}

Tidak ada hubungan yang bermakna antara asupan lemak dan RLPP dengan Kadar LDL pada Wanita Menopause di Posyandu Ngudi Waluyo Surakarta.

\section{DAFTAR PUSTAKA}

Adhiyani, C., 2013, Hubungan Usia dan Konsumsi Makanan Berlemak dengan Kolesterol Total pada Lansia di Kelurahan Serengan Surakarta, Program Diploma Akademi Analisis Kesehatan Nasional Surakarta, Surakarta.

Bull E dan Morrell J., 2007, Simple Guides Kolestrol, Edisi Ke-1, Erlangga, Jakarta.

Djohan TBA., 2004, Penyakit Jantung Koroner dan Hipertensi Ahli Penyakit Jantung, Skripsi, Fakultas Kedokteran, Universitas Sumatra Utara.

Fatmah., 2010, Gizi Usia Lanjut, Erlangga, Jakarta.

Khomsan, A., 2002, Pangan dan Gizi untuk Kesehatan, PT Raja Grafindo Persada, Jakarta.

Khomsan, A., 2003, Pangan dan Gizi untuk Kesehatan, Rineka Cipta, Jakarta.

Madanijah, S., 2004, Pendidikan Gizi dalam Pengantar Pengadaan Pangan dan Gizi, Penebar Swadaya, Jakarta.

Maulana M., 2007, Penyakit Jantung: Pengertian, Penanganan dan Pengobatan, Kata Hati, Yogyakarta.

Mueller, J And Nichols N., 2008, Waist to Hip Ratio Estimates Health Risk Are You an Apple or a Pear?, http://www.sparkpeople.com/resource/fitness_articles.asp?id=776, $\quad$ Diakses Tanggal 3 Maret 2015. 
Nuraeni D, Hidayati L dan Setiyono A., 2012, Hubungan Kebiasaan Konsumsi Lemak Jenuh dan Obesitas Sentral dengan Kolesterol Total pada Dosen dan Karyawan Universitas Siliwangi Tasikmalaya, Skripsi, Universitas Siliwangi Tasikmalaya, Tasikmalaya.

Putri, A.F., 2014, Hubungan Rasio Lingkar Pinggang Panggu dengan Kadar Kolesterol pada Wanita diatas Usia 40 Tahun di Lingkungan Sawahan Kelurahan Kepatihan Kecamatan Kaliwates kabupaten Jember, Skripsi, Program Sarjana Universitas Muhammadiyah Jember, Jember.

Soeharto, I., 2004, Serangan Jantung dan Stroke Hubungannya dengan Lemak dan Kholestrol, PT Gramedia Pustaka Utama, Jakarta.

Spencer, R.F dan Brown.P., 2007, Simple Guide Menopause, Dialihbahasakan oleh Julawita Surapsari dan Anna Koeswanti, Erlangga, Jakarta.

Sunarti dan Maryani.E., 2013, Rasio Lingkar Pinggang dan Pinggul dengan Penyakit Jantung Koroner di RSUD Kabupaten Sukoharjo, 16(1): 73-82.

Suparjo, H.P., 2010, Hubungan Rasio Lingkar Pinggang Panggul dengan Profil Lipid pada Pasie Penyakit Jantung Koroner (PJK) di Poliklinik Jantung RSUD DR.Moewardi Surakarta, Skripsi, Program Sarjana Universitas Muhammadiyah Surakarta, Surakarta.

Syafiq, A dan Fikawati S., 2013, Konsumsi Kalsium pada Remaja, Dalam Departemen Gizi dan Kesehatan Masyarakat (ed.), Gizi dan Kesehatan Masyarakat. Rajawali Press, Jakarta : 186-187.

Waspadji, S., 2003, Pengkajian Status Gizi, Studi Epidemiologi, FKUI, Jakarta.

Waspadji, S, Suyono S, Sukardji K dan Kresnawan.K.S.A.T., 2010, Pengkajian Status Gizi Studi Epidemiologi dan Penelitian di Rumah Sakit Edisi Kedua, Balai Penerbit FKUI, Jakarta.

Williams, L dan Wilkins., 2007, Ilmu Gizi Menjadi Sangat Mudah, Ed. 2. Dialihbahasakan oleh Dwijayanthi, L. EGC, Jakarta.

Wirakusuma, S.E., 2004, Tip \& Solusi Gizi untuk Tetap Sehat, Cantik dan Bahagia di Masa Menopause dengan Terapi Esterogen Alami, Gramedia Pustaka Utama, Jakarta. 